\title{
THE GENERAL NATURE OF THE CONDITIONS WHICH DETERMINE DEVELOPMENT.
}

$T$ HE saying of the witty Autocrat "that the brain often runs away with the heart's best blood" has its application to Philosophy, for every great system of thought springs from profound feeling-from an intense passion for order, a deep longing for unity. In the philosophy of science of the last few decades this was expressed in the conception of sociological phenomena as being organic, or even (at a somewhat earlier period) as in some important aspects physical; ${ }^{1}$ and more recently in the comparison drawn between the electronic atom and planetary groups. But the inadequacy of the conception of society as an organism has long been manifest; so that to-day some universal term is required that shall be truly all inclusive. and capable of expressing the concrete character (should there be one) of all reality.

But any such universal character, if it were also truly concrete, would be scientific as much as philosophic - it would be philosophical as expressive of all reality, and scientific as applicable to every reality. Two modern thinkers agree, however, though for widely different reasons, in rejecting any such identification of science with philosophy;-Bergson, because science is vitiated by the defects inherent in the intellect, and therefore cannot apprehend

${ }^{1}$ Cf. Bagehot's Physics and Politics. Plato had discovered much in common between the spirit of the individual and of the community. 
real duration; and Croce, because science is essentially non-philosophical, and employs not the true concept but always pseudo-concepts. ${ }^{2}$ On the other hand Hegel endorses this principle, at least formally; for his first category-Pure Being-although too abstract to permit the thought of "every reality," is still, while purely abstractly, expressive of "all reality"; on the other hand the supreme category-Idea or Spirit ${ }^{3}$ - would prove extremely difficult to apply directly in any sense consonant with the present usages of science. But if we follow Dr. McTaggart in his contention that the Hegelian Idea implies that "The Universe is differentiated. It consists of an organic system of individuals," we obtain at once a principle fundamental to all science both in its most general and in its most specialized aspects. The Universe is, in the first place, differentiated; as such it is a system (not for science but) for philosophy; and further, it is differentiated throughout - it is a system of individuals, each of which again is itself a subsystem, great or small as the case may be, and each, from this point of view, constituting the subject matter of some department of science."

If then the term "system" is given its widest and most profound meaning, it becomes equally applicable to all reality and to every reality, and thus the concrete universa! of philosophy finds its proper place also in the realm of science. It is certainly unfortunate that the usual meaning of "system" is narrow and specialized; we think of "business" or "memory systems" etc.; still even in these the really essential feature is present in the sense of the completest possible organization - the absence of all super-

2 Logic as the Science of the Pure Concept, p. 46.

${ }^{3}$ Cf. McTaggart, Commentary, sec. 294.

- Loc. cit. sec. 292 ; mathematical procedure is analogous in the transformation or degeneration of equations.

s Or other department of knowledge which cannot however, in view of the unity of all knowledge, be severed from science. 
finity and irrelevance. Instead then of regardings society e. $8 .$, as an organism, it is philosophically truer to look upon both alike as systems which, while differing in their special details, are similar in their possession of coherence, relevance and interconnection.

The universe again (still following here Dr. McTaggart's reading of Hegel) is an organic system; just as no organism is static, so is every natural system essentially dynamic - changing, evolving.enduring. Certainly we may, but only by limitation and abstraction, distinguish states of static equilibrim of shorter or longer duration; but this static aspect is always merely superficial or (in a sense) illusory and, always underlain by force or activity, is but a temporary though necessary stage in the total development: all states of equilibrium arise out of dynamic conditions which at the moment counteract each other. If then we assign to "system" the dynamic character which is distinctive of all living organisms, we are enabled (I think) to trace connections which unite or (to coin a word) "monify" categories of existence apparently widely separated, even if the actual detailed evidence for this is very' slight. In this way "vitalism" and "mechanism" become complementary to each other instead of being antagonistic : and I have previously encleavoured to prove that the development of the universe is necessarily a continous advance and never, as a whole, retrogressive.

At first sight, certainly, the concrete phenomena and conditions of this development are so infinitely diverse that knowledge seems compelled to remain always departmental: each science having its own distinct principles, appli. cable within its special sphere. but yielding at best only analogies, perhaps faint and distant, to other realms of

"I may refer to Scicucc Progress, No. 50. p. 305.

TThe Monist, April 1920, p. 203. Perhaps "development within the Universe" would be a better expression. How a Universe can truly develop is of course an extremely difficult problem. 
truth; thus the laws of motion are as foreign to psychology as are the principles of association to chemistry. Within limits, and mainly in the abstract sciences, this "irrelevance of determining principles," as it may be called, is slowly vanishing; thus mass and energy would appear to be identical, and all forces are probably electro-magnetic. ${ }^{8}$

How far then is it possible to carry this principle of the monistic transcendence of externality? To what extent is it possible to determine perfectly general conditions of development?-to express i.e. conditions which govern every type of change whether simple or complex, physical, vital, or social. Can we ascertain the universal characteristics of $(a)$ all embryonic or early stages, $(b)$ all mature and stable stages, whatever be the detailed course development may follow?

There has first to be considered the concept of "origin." Today it is almost a platitude to say that everything has, and indeed must have, an origin; but the obviousness of this assertion should not obscure two important points- $(a)$ that the problems of origin are always amongst the most difficult to solve and $(b)$ that earlier stages of knowledge, either explicitly or implicitly, assumed that these problems were actually insoluble, and fell back upon statements of which the opening words of Genesis may be taken as the type. Even today it remains true that no assigned origin is ever absolute, and that some degree of relativity, of arbitrariness, or even of conventionality, determines which stage or set of conditions is regarded as original. Subject to these considerations I should like to consider how far the

8 The irrelevance is at its minimum when knowledge is most abstract i.e. in pure mathematics, which may be regarded as an extensive and increasing application of a few simple principles, applicable also, directly or analogically, within formal or symbolic logic.

${ }^{9}$ This does not imply. however, that such utterances have wholly lost their value; at the same time this necessarily changes relevantly to the growth of knowledge as a whole. 
universal or perfectly general attributes of "origin" can be ascertained.

Every origin, in the first place, however simple it may be, must possess some degree of systematic structure, which again must be, either patently or covertly, of such a nature that some measure of continuity (or in more philosophic language, identity),${ }^{10}$ exists between it and all later stages. Here again we are often driven back upon more or less arbitrary principles in order to establish such continuity. How far e.g. is it true to say, in view of the immigrant flood, that the national characteristics of the United States are identical with those of the thirteen colonies? and the same problem appears in a different form if we ask how the ingestion of food and the resultant tissue renewal bear on the identity of the organism.

But wherever there arises this difficulty of determining, from among any series of connected stages, the actual origin, it plainly indicates the absence of any absolutely distinctive criterion; it implies (in other words) that all the stages, whatever their degree of difference may become, are still alike in the possession of some common quality. This universally common quality is (once again) systematic structure; development, that is, in all cases and at every stage consists in the combination ${ }^{11}$ of different constituent systems among which, as systems, it is frequently very difficult or indeed impossible to determine the essential origin and continuity; and it is only when one of the many systematic structures becomes in itself obviously dominant that it is selected as the real origin, or basis of true continuity. But this dominance or obviousness is always plainly a matter of degree and of relativity; the immigrants e.g. during

${ }^{10}$ Not however the bare identity $A=A$ of formal logic. It is obvious that till this abstract self-identity is somehow transcended no knowledge is at all possible.

11 In exceptional cases, dissociation, which is merged however in some later combination. 
any selected brief period are much more loosely connected than are the Lnited States of that same period: on the other hand, if the German invasion of Belgium had succeeded, the Belgian nationality would have been so radically altered that history would probably have been compelled to recognise a new "origin," as it has often done in times when armed conquests were the rule rather than the exception.

For a philosophy or knowledge ideally complete then every such contributory system would be equally essential, because such a final philosophy would possess the Absolute as its criterion of universal relativity: $:^{12}$ our actual knowledge, however. must in its inconpleteness adopt now one criterion and now another: thus, to cite one example, in the evolution of humanity "origin" and "continuity" assume wholly different aspects according to whether we view personal development as an end in itself, or as contributory to the existence of nationality or humanity as a whole.

But further, in thus insisting on the necessity of the conception of systematic structure, it is obvious that we have passed beyond the consideration of mere change as such. The idea of change merely in itself is superficial and abstract, and of little value beyond very limited ranges of phenomena.": Change must be regarded as occurring always within a systematic universe, and as itself therefore sharing in and contributing to its systematic nature; thus viewed it becomes the abstract aspect of some concrete developinent, and denotes in reality the progressive combina. tion of diverse systems into an increasingly complex whole.

12 It seems too often forgotten that "relativity" is itself relative; therefore not being itself absolute, it necessarily implies an absolue; as e. $g$. Time in Newtonian mechanics, and "proper time" in relativity mechanics.

${ }^{18}$ But the concept of change has always held a prominent place in philosophy from the $\pi$ ávra $\zeta \in i$ of Heracleitus to our own day. $C f$. c.g. "What I find when I look at consciousness is a sequence of different feelings." (Shadworth Hodgson, Philosophy of Reflection, vol. I. p .248.) "Such a description", comments James, Principles of Psychology, Vol. I, p. 230), "can awaken no possible protest." 
I think it is important to notice that this is not a conclusion which, at the present level of knowledge, can be obtained on mere a priori grounds; even if there are (as I believe) sound general philosophic reasons in its favour, still a "kaleidoscopic" universe-one i.e. in which perfectly haphazard changes constantly occurred which, though governed by law, still served no final end-does not seen prima facie to be wholly inconceivable; and in what sense such a world could be regarded as truly systematic is a diffcult question.

Actual experience, however, presents to us development from origins; thus far we have seen that in all cases where it is difficult to discover the true origin, this difficulty resolves itself into that of the lack of criteria which enable us to select from among the many cooperating systems any one that is indubitably basal and dominant. But this conclusion has an obverse aspect which I should now like to consider-the problem i.e. of those attributes on which our choice of origin is actually based in cases where it proves to be quite well founded.

One such attribute that is very often insisted upon is the simplicity of origins: but this merely in itself is plainly an insufficient, and may even become a wholly misleading, criterion; and this for two reasons- $(a)$ because simplicity is itself always relative, and $(b)$ because every stage in development is in some aspects simpler than succeeding stages. It is true that we can often trace this increasing simplicity back to a point where a single further step would bring us to an earlier system which itself appears highly complex, and we then feel justified in placing the line of distinction between such a "parent" system and the "simple" system which springs from it." But however legitimate

14 The living germ is the most obvious instance; but this should, for conscious beings, include mental phenomena, which vastly increases the difficulties. But almost all social origins are on the same footing as regards their simplicity. 
this procedure may be, it raises two obvious difficulties(a) as to the nature of the "simplicity" of the origin and (b) as to its relation to its own previous origin or parent system.

In the first place, it seems exceedingly doubtful whether the "simplicity" thus attributed to origins has any actual existence; here we may often be completely deceived by appearance. Certainly all investigation shows that the living germ is exceedingly complex-as complex indeed in one way as is the adult organism in another; and this again is confirmed by the degree in which the germ itself largely determines the total course of development, which then comes to resemble the breaking down or the unfolding of a preexisting highly complex but much condensed structure; an interpretation which is still more obvious in the case of the radioactive elements. Here then it is not so much a question of different degrees of complexity as of different modes, and of the gradual conversion of one mode into the other. Expressed again in still more general terms, all germinal stages appear to have a higher degree of potentiality than the later, so that in this respect the usual contrast as to simplicity is actually reversed. If we compare e.g. the spiritual endowments of the "simple" early Roman republic with those of the "complex" but decadent Empire, there can be no doubt as to which possessed the greatest potential capacity; in all such cases the child is, in a very real sense, the father of the man. And whatever were the defects of the earlier "preformation" or emboitement theories of vital development they at least recognized and expressed (if only by implication) the high complexity of all the various stages.

Thus the essential character of origins is not so much the degree, as the mode, of their complexity. Their systematic structure is such that each of the constituents, while 
all remaining united together, is capable of entering into a series of combinations continuously, until a new system has been constructed whose elements are so combined inter se that few new combinations remain possible. It is obvious that in both cases alike the degree of complexity must be very high; the only difference then must be between the two modes; for only a highly complex system will be capable of providing the innumerable bases and connections whereby the resultant system can arise; only an exceedingly complex structure can be thus active and potential, and the simplicity so often ascribed to origins is very largely illusory and abstract.

Development then-i.e. the change from original systems to adult-is best interpreted not as an increase in, but as a continuous transformation of, the mode of the complexity of the developing system; and it is obvious that if this transformation were to become complete, development would thereupon cease. In individual cases it does thus come to an end; and the transcendence of this finality is rendered possible only by the conservation, in some way or other, of that special mode of complex structure characteristic of original systems. The most concrete instance is that of the reproductive elements in living organisms; but analogous phenomena occur wherever we find expansion and development-in the spiritual faculties of creative genius-in the adventurous and enterprising members of a nation, be that primitive and obscure or mighty and famous. Thus the maintenance of universal development depends on the union, in all the component individual systems, of two radically different modes of complex structure-the one stable, more or less rigid, narrowly specialized in some limited direction, and therefore incapable of functioning in any other way; and from this arise the elements of regularity and mechanicality; - the other able to enter into a 
long series of widely diverse combinations between which it functions as the common basis of union, and so contributes to the universe the contrasted characters of infinite plasticity and originality,-l'élan rital.

Reality, then, regarded as a developing whole, everywhere presents these two widely differing aspects; but it is fundamentally important to note that each is indispensable to the other, without whose activity it could not itself exist. This universality of mechanism in the world has always been a serious stumbling block to every philosophy that has considered itself idealistic: its apparent want of that freedom supposed to be inherent in mind or spirit has made it difficult to explain, while its patency makes it equally impossible to explain it away. On the other hand it has been as fully misinterpreted in the opposite direction by those crude materialisms which have taken it to prove that all spiritual values are only epiphenomenal; even Lotze, who, despite his wide scientific knowledge was no materialist, seeks its justification in that direct appeal to "divine wisdom,"1s which is always a confession of philosophic bankruptcy. Bergson indeed does in a sense attempt to explain it away by regarding the mechanical as but the distortion, due to the intellect, of the true character of reality : and the basal defect of his system consists in this exaggerated insistence on the "durational" aspect of the world and the consequent unjustified depreciation of all mechanism. It is necessary. of course, to draw between them a profound distinction; and it is probably inevitable that every philosophic system must somewhere place too marked an emphasis; but Bergson's dichotomy is altogether too absolute. For he regards two elements which are in truth complementary and so equally real, the one as merely illusory, while only its fellow

15 "Conceiving it not as a self supporting fate but merely as a product of divine wisdom;" Microcosimus, Vol. I, p. 399. 
is truly real; and two correlatively different methods of apprehension again-the one intellective, the other intuitional-then subserve our full consciousness of real being. But such an attitude wholly misinterprets the status of those fixed and completed elements in the world which are the fruits of its eternal process; between these and the processes which brought them into being there need be no antagonism whatever, provided they themselves conserve and maintain, as they obviously do, the means necessary for further development; each then-process and product, the mechanical and the dynamic - is the indispensable basis and complement of the other; nor does any impassable barrier prevent the mind from apprehending the real nature of either; for thought, even when farthest removed from full reality, is a self-condemned exile, and finds, as genius ever does, new life and strength in the deserts of abstraction, whence it returns armed with weapons still more powerful for its conquest of the concrete.

There still remains to be considered the question: In what consists the specific potentiality and complexity of all origins as such? What enables them to initiate and control new courses of development? - new i.c. even as individual instances of some generic type, much more when there is no pre-existent class to which they must conform.

The essential characteristic appears to be the advanced level of organisation which all origins possess, relatively (a) to their parent systems and ( $b$ ) to the environment in which they can best function. In some respects or other this plane of organisation is always higher than that of hoth the environment and the parent source; and therefore every element in such an original system $^{28}$ is capable of entering into combination with other systems which are

\footnotetext{
${ }^{10}$ Except those necessary to maintain the system's existence as an origin: e.g. the cell wall of organic germs.
} 
(ex hypothesi) lower in the level of organisation than itself ; for none of these constituents can find its proper complement, or can satisfy its powerful affinities, within the limits of the origin itself. The resultant systems again are (also ex hypothesi) incapable of repeating that precise form of combination from which they arose, so that the original capacity for combination becomes automatically more and more limited at every stage in the process; in other words the potentiality of combination necessarily falls as the stability or fixity of the resultant system rises. Potentiality becomes gradually converted into actualitythe dynamic into the static ${ }^{17}$ - the "durational" into the mechanical-without however either of these two fundamental aspects acquiring a degree of reality superior to that of the other, as is contended (in one direction) by the philosophies of materialism or of mechanical determinism, and (in the other) by the intuitional philosophy of Bergson.

If we venture to carry the enquiry still a stage further, and to seek the ground of this higher level of organisation to which all origins attain, we can only fall back (I think) on some such general philosophic principle as I have endeavoured to establish in a previous number of The Monist ${ }^{18}$ but a few additional remarks may be helpful regarding the difference which exists between the possibilities of organic, and of sociological or historic development.

Regarding the phenomena from the widest possible standpoint, the plasticity of organic development may be called specific rather than individual; the limits of the group i.e. appears to be more elastic than those of the individual, whose development is in the main confined to a fixed course from which little deviation is possible. This seems to be true whatever importance mutation theories may prove to

17 But see the previous remarks on the relation between these.

${ }^{18} \mathrm{Cf}$. note 7 ante. 
possess; for unless a group mutates, the variation is almost inevitably swamped so that reversion to type is assured.

This appears to depend on two causes- $(a)$ the fixed character of the organic germ, which again is a necessary result of its material nature; and $(b)$ the comparative constancy of the environment of the organic world, which also arises from its material constitution. To what degree the germ plasm is alterable by external influences is still a vexed question, and the inheritance of acquired characters an open problem. The invariability of the environment, again, both as regards its organic and its inorganic factors, is largely relative; nevertheless the operation of these two causes taken together would appear to explain the rigidity (as it may almost be called) of the course of organic development in the individual.

Social and historic progress, however, is on an entirely different plane. Freed from the bonds which confint the world of matter, wholly new influences come into play whose range and capacity are infinitely wider than those which rule the organic ${ }^{10}$ and though History may repeat itself in principle, it can never do so in details. All spiritual development therefore, both national and individual, proceeds within an environment which is itself rapidly developing, and every evolving system becomes an active and powerful factor in modifying the growth of its fellows. It is difficult to say in this respect whether personal or group action is the more effective-whether, in other words, the "great man theory" of History is well or ill founded. The same influence is operative in both cases, but is more concentrated in one than in the other. In every community destined to achieve greatness there must exist (as we have seen already) groups and institutions capable of combining with others, it may be externally through colonisation or

10 "The Genesis of Freedom." International Journal of Ethics, April, 1920. 
territorial expansion. On such a community the action of a vigorous personality is comparable to that of an enzyme or catalyst; it controls the social groups which it finds ready to hand and amenable to its influence, having the advantages of more rapid responsiveness to opportunity and less inertia than the group. On the other hand the conservatism of the group acts like a fly wheel and ensures some measure of persistence and continuity.

A few final remarks on the conditions governing the material basis of organic germs may not be out of place. During the protracted fall which preceded the solidification of the earth the formation of chemical compounds would plainly depend on two factors- $(a)$ the quantity of the combining elements and $(b)$ the strength of their affinity; both of these, again, depend on the electronic structure of the atoms. Their quantity varies with the readiness with which the electrons finally unite to form any stable atom, and the affinity of the attraction between the various electronic systems thus formed. An increased knowledge of atomic structure may reveal laws which express some constant connection between the chemical activity of atoms and their quantitative distribution. ${ }^{20}$

The continuous temperature fall again would necessitate the postponement of those combinations, due to the weaker affinities, which are possible only at low temperatures and in which the attractions are comparatively so feeble that the resultant compounds are extremely sensitive to external influences. This raises the problem as to how the elements concerned in these could be maintained in combination, particularly in any complex compound; probably radiation and enzyme action are among the active factors.

20 The great range of carbon compounds appears to be connected with the exceptionally high frequency of its atomic vibrations. Gases, again, lead to maximum molecular disorder. 
One further important principle seems to be obviousthat in all such complex and sensitive systems the various elements can be present only in extremely small quantities. because only so could they all be brought effectively within the range of mutual action. Thus there is an order of quantity, acting as a limit applicable to all the elements, which cannot be transcended without destroying this sensitive complexity; plainly again, should any one element increase in quantity, each of the others must increase pro rata to maintain that particular combination as such. This would be one factor regulating the volume of the organic cell.

These principles may be further extended to complex structures other than purely chemical-to all complex systems which are in consequence highly sensitive to external stimuli; in all these the quantity of each constituent must be relatively small, otherwise (as e.g. in the brain) the total quantity requisite for complexity would become too unwieldy. Similarly the non-spatial character of ideal and spiritual attributes cnables them to co-exist in their immense variety, so as again to ensure extremely sensitive complexity; and if any man frets because of his personal obscurity and transience, it may console him to realise that these are necessary conditions of all existence within a highly organised universe.

\section{J. E. Turner.}

LiVERPOOL, ENG. 